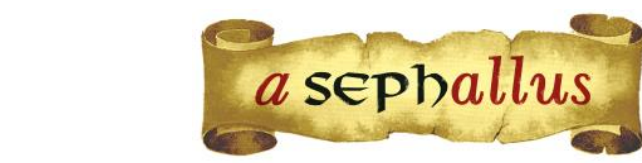

Revista aSEPHallus de Orientação Lacaniana

Núcleo Sephora de Pesquisa sobre o Moderno e o Contemporâneo

ISSN $1809-709 \mathrm{X}$

\title{
Bases conceituais para o entendimento da identificação na melancolia: da identificação ao objeto perdido à identificação à face real do objeto $a$
}

Clarissa Maia Esmeraldo Barreto (orientanda) Graduação em Psicologia / UFC (Fortaleza, Ceará, Brasil) Mestranda em Psicologia / UFC (Fortaleza, Ceará, Brasil)

E-mail: clarissaesmeraldo@gmail.com

\author{
Laéria Fontenele (orientadora) \\ Professora Associada III da Graduação e da Pós-Graduação em Psicologia da \\ Universidade Federal do Ceará (Ceará, Brasil) \\ Doutorado em Sociologia / UFC (Fortaleza, Ceará, Brasil) \\ Diretora do Corpo Freudiano Escola de Psicanálise - Seção Fortaleza \\ E-mail: laeria@terra.com.br
}

\begin{abstract}
Resumo: Pretendemos contribuir para o esclarecimento do processo de identificação que Freud denominou como objeto perdido na melancolia. Para tanto, discorreremos sobre o desenvolvimento freudiano do conceito, partindo de alguns dos seus escritos pré-psicanalíticos, para desembocarmos no texto principal a respeito da afecção melancólica (Freud, 1917[1915]/2004). Iremos, ainda, relacionar os achados da teoria freudiana com as proposições de Lacan acerca do referido objeto, considerando para tanto o período situado desde o seu seminário sobre $A$ ética da psicanálise até o seminário sobre $A$ angústia. Por fim, discutiremos sobre como, a partir das conjeturas sobre o estatuto do objeto perdido, ocorre o processo de identificação característico da afecção melancólica.

Palavras-chave: psicanálise; melancolia; objeto perdido; identificação.
\end{abstract}

Bases conceptuelles pour comprendre le processus d'identification chez la mélancolie: dès I'identification avec l'objet perdu à l'identification avec la face réelle de l'objet "a"

Dans cet article, nous souhaitons comprendre le processus psychologique d'identification nommé par Freud comme l'objet perdu chez la mélancolie. À cet effet, nous analyserons le développement freudien de ce concept à partir de certains de ses écrits prépsychanalytiques pour enfin parvenir à l'analyse de l'œuvre la plus importante en ce qui concerne l'affection mélancolique chez Freud (Freud, 1917[1915]/2004). Nous souhaitons comparer les conclusions de Freud aux propositions de Lacan à l'égard de l'objet $a$, en considérant à cet effet la période entre les séminaires L'étique de la psychanalyse et L'angoisse. Enfin, nous traiterons de la façon selon laquelle, à partir des conjectures à propos du statut de l'objet perdu, a lieu le processus d'identification qui charactérise l'affection mélancolique.

Most-clés: psachanalyse; mélancolie; objet perdu; identification.

Conceptual basis for the understanding of the identification process in melancholia: from the identification with the lost object to identification with the real face of the object "a"

In this paper, the authors propose to shed a light on the psychological process of identification that Freud called the lost object in melancholia. To that end, the authors examine the Freudian development of this concept through some of his pre-psychoanalytic writings, and end this analysis with Freud's most significant work regarding melancholia's psychogenic affection (Freud, 1917[1915]/2004). The authors also compare the freudian findings to Lacan's propositions concerning the above-mentioned object, taking into consideration theories from the period between Lacan's seminars The ethics of psychoanalysis and Anxiety. Finally, the paper considers how, from conjectures on the statute of the loss-object, the process of identification that is so representative of melancholic affection, occurs.

Key-words: psychoanalysis; melancholia; lost object; identification. 


\section{Bases conceituais para o entendimento da identificação na melancolia: da identificação ao objeto perdido à identificação à face real do objeto $a$}

Clarissa Maia Esmeraldo Barreto \& Laéria Fontenele

\section{A melancolia e o objeto enquanto perdido}

Freud iniciou seus estudos sobre a melancolia no final do século dezenove, ocasião em que suas concepções ainda estavam bastante relacionadas com sua formação em neurologia. Apesar de seu caráter inaugural e de sua anterioridade ao próprio conceito de inconsciente, tais estudos são fundamentais para compreendermos o que ele chamará posteriormente de objeto perdido quando se refere à melancolia.

Em seu principal rascunho sobre o tema, Freud (1895/2006) caracteriza a melancolia a partir dos destinos da libido, afirmando que o luto seria o afeto que the é correspondente. Manifestandose no desejo de recuperar algo que foi perdido, ela consistiria em um luto devido à perda da libido e não de um luto qualquer, sendo este fator que diferirá a melancolia dos estados de luto considerados normais, trabalhados por Freud vinte anos depois, no texto canônico "Luto e melancolia" (Freud, 1917[1915]/2004). Além disso, pensar essa afecção como caracterizada por um luto diante de uma perda de libido esclarece por que ele afirma que a perda da qual sofre 0 melancólico é de ordem inconsciente, mesmo sendo conhecida a circunstância: "se o doente sabe quem ele perdeu, não sabe dizer o que se perdeu com o desaparecimento desse objeto amado" (Freud, 1917[1915]/2004, p. 105, grifo do autor). A fim de explicar a natureza disso, Freud (1895/2006) parte de um diagrama esquemático da sexualidade, ou seja, das comunicações estabelecidas pelos neurônios entre si, examinando as circunstâncias nas quais um grupo sexual psíquico sofre um decréscimo na sua excitação. Freud (1950[1895]/2006), desde o "Projeto para uma psicologia científica", propõe uma teoria energética do aparelho psíquico pela via da organização neuronal. Esse arranjo consiste na presença de uma energia sexual somática que se acumula até certo ponto, causando desprazer. Esse acúmulo de tensão física, ao atingir certo limiar, transformase em energia sexual psíquica. Esse mecanismo comporta três formas de falhas, sendo a melancolia decorrente de uma delas.

Para o autor, a melancolia ocorreria quando a produção de excitação sexual somática diminui ou chega a se interromper, caracterizando a sua forma grave ou cíclica, em que há alternância da produção de excitação. Existe ainda a possibilidade de a excitação ser desviada do grupo sexual psíquico, estando a produção de excitação sexual somática mantida e utilizada em outra parte. Em todo caso, haveria uma impossibilidade de descarga de energia psíquica, pois não haveria um objeto ao qual essa tensão pudesse se ligar e efetivar a descarga adequada.

Esses estudos servem de guia para compreendermos a relação evidente entre melancolia e anestesia. Esta se constitui sempre por omissão da sensação voluptuosa, que deveria ser direcionada ao grupo sexual psíquico logo após a ação reflexa que descarrega o órgão efetor. Nos casos de 
frigidez, a anestesia não se configura como causa da melancolia, surgindo-lhe como um indicativo de predisposição. Em outros casos, no entanto, Freud (1895/2006) afirma que a anestesia é uma causa da melancolia devido às alterações da sensação voluptuosa. A anestesia se configura como um sinal da melancolia, já que o sujeito pode ser anestésico sem ser melancólico e o grupo sexual psíquico possui influência tanto devido à ausência da sensação voluptuosa como da excitação sexual somática.

A partir desse esquema do grupo sexual, em que a ausência de tensão física no órgão efetor caracteriza uma predisposição à melancolia, Freud explica os efeitos dessa afecção, descritos como "inibição psíquica, com empobrecimento pulsional e o respectivo sofrimento" (Freud, 1895/2006, p. 252, grifo do autor). No momento em que o grupo sexual psíquico depara com uma grande perda da quantidade de excitação (devido à ausência de tensão no órgão efetor), acontece uma "retração para dentro" (Freud, 1895/2006, p. 252, grifo do autor), no domínio psíquico, que resulta numa diminuição da quantidade de excitação em geral, já que os neurônios adjacentes são obrigados a se desfazer de suas associações, como uma espécie de sucção. Para Freud, desfazer associações sempre produz sofrimento, sendo isso o que faz com que, nesse momento, seja lançada a ideia de uma hemorragia interna que serve à descrição dos fenômenos psíquicos compreendidos na melancolia. Esse processo de retração atua como uma ferida, que atrai para si todo tipo de investimento, de maneira análoga ao que ocorre nos estados de dor, e ilustra o buraco na esfera psíquica com o qual Freud explica, nesse período, a melancolia.

Parece ser possível o estabelecimento de uma equivalência entre a organização neuronal do aparelho psíquico e as proposições significantes desenvolvidas por Lacan no seu segundo e sétimo seminários, o que equivale a dizer que a transmissão entre os neurônios se assemelha à cadeia de pensamentos inconscientes (Quinet, 2006). Diante disso, quando Freud fala em desfazer associações, podemos interpretar como dissolução da cadeia associativa, resultando em uma carência de representações, fenômeno que produz dor e sofrimento na melancolia. Tal dissolução corresponderia ao buraco no psiquismo por onde escorre a libido, o que nos leva a pensar que a perda característica da melancolia não pertence ao registro das palavras, mas ao da Coisa.

Nesse sentido, o polo oposto ao da melancolia seria representado pela mania, "na qual o excedente de excitação se comunica a todos os neurônios associados" (Freud, 1895/2006, p. 252). Pensando nisso com Lacan, observaríamos, na mania, um deslizamento incessante de significantes na cadeia, como se houvesse um triunfo sobre o processo melancólico, o qual pode ser percebido nos episódios de fuga das ideias (Quinet, 2006). Dessa forma, mania e melancolia fazem parte de uma mesma estrutura, na qual, o que dela padece pode se encontrar ora no polo melancólico, ora no polo maníaco.

Freud (1950[1895]/2006), no texto "Projeto para uma Psicologia científica", dando prosseguimento ao discernimento acerca do que é especificamente perdido na melancolia, apresenta um esquema quantitativo do aparelho psíquico cujo princípio é manter a tensão próxima a zero - 
princípio de inércia -, a partir da descarga de uma determinada quantidade (Q) de estímulos. Quando o estímulo é proveniente do mundo externo, a descarga geralmente se dá a partir de funções que "envolvem a cessação do estímulo: fuga do estímulo" (Freud, 1950[1895]/2006, p. 348, grifo do autor). No entanto, Freud foi percebendo que, à medida que o organismo se torna mais complexo interiormente, o princípio de inércia encontra dificuldades para ser mantido, já que o sistema nervoso também recebe estímulos internos (Q⿱宀) que também precisam ser descarregados. Desses estímulos, diferentemente do que ocorre com os estímulos externos, o organismo não pode se esquivar, de forma que certas ações específicas devem ser realizadas no mundo externo a fim de provocar a cessação dos estímulos endógenos.

Tendo em vista tal impossibilidade de fuga, o organismo é obrigado a abandonar a tendência à inércia: "Precisa tolerar [a manutenção de] um acúmulo de Q̀ं suficiente para satisfazer as exigências de uma ação específica" (Freud, 1950[1895]/2006, p. 349, grifo do autor). De agora em diante, o sistema nervoso deve trabalhar para manter o nível de energia do aparelho psíquico em uma constância, de acordo com o princípio de prazer, o qual determina que quanto maior a quantidade de excitação, maior o nível de desprazer experimentado e maior a necessidade de descarga.

Freud nomeia três conjuntos de neurônios associados que são responsáveis pelo controle dos estímulos: $\phi, \Psi, \omega .0$ sistema $\Psi$ representa a centralidade do aparelho psíquico, recebendo tanto estímulos endógenos, quanto estímulos externos fracionados a partir de $\phi$. Os estímulos endógenos, que possuem caráter intermitente, produzem-se de forma contínua e se transformam em estímulos psíquicos ao atingir determinado limiar, cuja resistência da via de facilitação é superada após o aumento da quantidade. Essa força interna constante será nomeada por Freud de "vontade - o derivado das pulsões" (Freud, 1950[1895]/2006, p. 369, grifo do autor).

A criança de tenra idade encontra-se em posição de desamparo em relação às ações específicas, necessitando da ajuda de um outro para produzir uma modificação no meio que resulte na cessação provisória dos estímulos endógenos. Este processo é chamado de experiência de satisfação e se caracteriza pela descarga que eliminou a percepção de um estímulo desprazeroso em $\omega$, conjunto de neurônios responsável pelas indicações de qualidade e realidade do objeto. Posteriormente, produz-se, no sistema de neurônios $\Psi$, o investimento de um neurônio que corresponde à percepção do objeto e, a partir disso, em outros pontos do sistema $\Psi$, chegam as informações de descarga, estabelecendo uma facilitação entre as catexias e os neurônios nucleares.

Quando esse estado de urgência ou de desejo reaparece, ocorre novamente a catexização da imagem do objeto que promove a satisfação, dando início ao processo de descarga. No que se refere à relação com o objeto, tema que é central para nossa presente discussão, Freud (1950[1895]/2006) atesta existir a possibilidade de que, simultaneamente à catexia de desejo da imagem mnêmica, esteja presente a percepção dela. Afirma, no entanto, ser mais comum encontrar uma situação em que a catexia de desejo está presente, mas a percepção não corresponde a ela 
inteiramente. Encontramos aí uma das mais importantes proposições freudianas sobre o objeto, a qual se relacionará com a perda libidinal presente na melancolia. Freud supõe que a catexia de desejo se relaciona com o conjunto de neurônio $a+b$, e a catexia perceptiva, com os neurônios $a$ $+c$, diz ele:

Comparando o complexo perceptual com outros complexos congêneres, pode-se decompô-lo em dois componentes: o primeiro, que geralmente se mantém constante, é o neurônio $a$, e o segundo, habitualmente variável, é o neurônio $b$. A linguagem aplicará mais tarde o termo juízo a essa análise e descobrirá a semelhança que de fato existe [por um lado] entre o núcleo do ego e o componente perceptual constante e [por outro] entre as catexias cambiantes no pallium e a componente inconstante: esta [a linguagem] chamará o neurônio a de a coisa, e o neurônio $b$, de sua atividade ou atributo - em suma, de seu predicado. (Freud, $1950[1895 / 2006$, p. 380, grifos do autor)

Consoante Freud, a primeira experiência de satisfação (neurônio a) produz a inscrição de algo, que é "uma parte constante e incompreendida" (Freud, 1950[1895]/2006, p. 439) - nomeada por ele de a Coisa (das Ding) -, e outro componente variável e compreensível - os atributos. 0 pensamento surgiria a partir do momento em que a catexia de desejo e a de percepção não coincidiriam, estando sempre presente uma tentativa de se alcançar o objeto que correspondeu à primeira experiência de satisfação (neurônio a), mas este, no entanto, encontra-se perdido para sempre. Partindo disso, o sujeito se relacionaria sempre com algo derivado dessa experiência inaugural de identidade (neurônio $a+c$, neurônio $a+d \ldots$ ), ocasionando a inscrição do sujeito no universo simbólico.

Na origem no aparelho psíquico há, pois, a inscrição de um traço mnêmico de um objeto que corresponde à primeira experiência de satisfação. Esse objeto, enquanto perdido, é buscado em todas as experiências de satisfação seguintes, por meio de seus atributos variáveis que se mantêm constantes. Essa perda é estruturante do aparelho psíquico, o que nos leva a indagar como ela vai se relacionar especificamente com a perda de libido mencionada por Freud no "Rascunho G", quando da sua posterior caracterização da melancolia.

\section{A Coisa em "Luto e Melancolia"}

O trabalho de Freud (1917[1915]/2004) sobre o luto e a melancolia tomou corpo graças ao seu desenvolvimento dos conceitos de narcisismo e ideal de eu, responsáveis por impulsionar seu estudo sobre as psicoses. É ele, pois, central para pensarmos a melancolia, dentre as psicoses, como resultado de uma perda específica. 
Nele, a proposta de estudar a melancolia comparativamente aos estados de luto justifica-se devido às circunstâncias que os fazem coincidir em determinados aspectos. 0 processo de luto é um trabalho decorrente da perda de um objeto que demanda um dispêndio de energia envolvida na constatação de que, na realidade, ele não mais existe - lembremos o conjunto de neurônios $\omega$ descrito por Freud no "Projeto" como indicadores de qualidade (Freud, 1950[1895]/2006) -, de forma que a retirada de libido, antes ligada a tal objeto, faz-se necessária. Esse processo é realizado paulatinamente, visto que os humanos possuem dificuldades em abandonar uma via de satisfação antes adotada, acarretando uma forte oposição, que pode ser tão intensa que produza um afastamento da realidade por meio de uma "psicose alucinatória de desejo" (Freud, 1917[1915], 2004, p. 104). O respeito pelo teste de realidade é, assim, alcançado aos poucos, mediante intenso consumo de energia que, de certa forma, prolonga a existência do objeto. Findado tal processo, o eu acha-se livre e desinibido para realizar novos investimentos objetais.

Embora a melancolia possua características semelhantes às encontradas no luto - desânimo, dificuldade de estabelecer laços amorosos, inibição psíquica -, uma lhe é particular: a diminuição do sentimento de autoestima, percebido como autorrecriminações e autopunições que margeiam a expectativa delirante por punição. Como trabalhado desde o "Rascunho G", Freud (1917[1915]/2004) reitera que a perda característica da melancolia é o processo que escapa à consciência por estar fora do registro das representações de palavras. Por isso, o empobrecimento do eu, ausente no processo de luto.

É premente que luto e melancolia diferem tanto quantitativa quanto qualitativamente. A segunda apresenta efeitos mais severos do que o primeiro, caracterizando-se por um sentimento de depressão mais profundo, uma perda extremada de interesse pelo mundo externo e uma tormentosa inibição. No entanto, é do ponto de vista qualitativo que percebemos a maior distinção entre os dois processos: a remissão a uma perda de um objeto que não se especifica, conferindo à melancolia um estatuto particular.

O traço específico dessa é, pois, uma perda que se passa no registro do inconsciente, na zona das representações de Coisa (das Ding). Essa peculiaridade nos leva a pensar em um desligamento da Coisa de seus atributos (o desligamento de associações), geradora de esvaziamento de libido e de dor (Freud, 1895/2006).

A diminuição do sentimento de autoestima expresso sob a forma de intensas recriminações voltadas ao eu do melancólico justifica-se pelo empobrecimento pulsional evocado no esquema do grupo sexual (Freud, 1895/2006). Quando tal grupo depara a diminuição da sua quantidade de excitação e seu posterior desligamento de associações, forma-se o, já citado, buraco no psiquismo. Donde a célebre afirmação freudiana: "No luto, o mundo tornou-se pobre e vazio; na melancolia, foi o próprio Eu que se empobreceu" (Freud, 1917[1915]/2004, p. 105). No entanto, ainda não está bem especificado o que absorveria tão violentamente o eu dos melancólicos e ocasionaria uma inibição de origem mais enigmática do que a que ocorre no luto. Quadro que se completa com a 
visível perda de força da pulsão que impele todo ser vivo a apegar-se à vida, podendo levar o melancólico ao suicídio.

Se associarmos o conceito de pulsão de vida à ideia de estado de urgência, presente no Projeto - que movimenta a cadeia representacional em busca dessa primeira experiência de satisfação -, pode-se pensar que o sobrepujar melancólico da pulsão de vida remete ao desligamento entre a Coisa e seus atributos em virtude do buraco na esfera psíquica por onde escoa a libido, empobrecedor do eu, que nada mais é do que o precipitado de traços dos objetos (Freud, 1923/2007). Esse fator é ilustrado por Freud ao afirmar que "uma representação mental inconsciente do objeto está sendo abandonada pela libido" (Freud, 1917[1915]/2004, p. 114), de onde podemos retornar às ideias trabalhadas no "Projeto" sobre o neurônio $a$, parte constante e incompreendida. No original, não se trata de die Sache, mas sim da própria das Ding. A escassez dos atributos da Coisa incita a uma relação mais direta com a mesma, a qual ilustra como os processos característicos da melancolia são de ordem inconsciente, onde imperam os traços mnêmicos de coisa, explicando, assim, a perda específica de objeto.

Quando Freud atesta que o melancólico, devido às autopunições, está falando a verdade e que se aproxima mais do autoconhecimento do que outros, somos levados a concluir que tal se daria justamente devido a sua relação mais radical à Coisa que, no caso, encontra-se destituída de traços que the poderiam conferir uma imagem.

Devido ao conflito de ambivalência, a relação com o objeto na melancolia possui um fator agravante, podendo ser: inerente a cada um dos investimentos objetais do eu; de origem constitucional ou surgir das experiências diante da ameaça de perda do objeto. De acordo com Freud (1917[1915]/2004), a melancolia pode ir bem mais longe do que o luto, no que se refere às causas que a determinam. Nela, banhadas pelo conflito de ambivalência, inúmeras batalhas em torno do objeto são travadas e, nessas, o ódio concorre desligando a libido do objeto, já o amor age em defesa de um tal domínio da pulsão de morte.

\section{Uma introdução à Coisa em Lacan e sua relação com o objeto $a$}

Lacan (2008) inicia seu seminário sobre a ética da psicanálise diferenciando os vocábulos usados em alemão para designar a coisa: das Ding e die Sache. Estabelece, aí, a relação das mesmas com o termo Wort (palavra). Os dois primeiros termos, embora significando "coisa" em português, aludem a acepções diferentes na língua alemã, de forma que die Sache refere-se, originalmente, a uma operação jurídica, "é a coisa colocada na questão jurídica, ou, no nosso vocabulário, a passagem à ordem simbólica de um conflito entre os homens" (Lacan, 2008, p. 58).

Sache e Wort encontram-se ligados, formando um par. Freud emprega os termos Sachvorstellung (representação de coisa) e Wortvorstellung (representação de palavra) e mostra, com isso, a existência de uma ligação entre coisa e palavra. Sache seria a coisa como produto da ação humana enquanto submetida pela linguagem. Quanto a das Ding, Lacan (2008) afirma ser ela 
algo diverso e estaria situada em outro lugar: "O que há em das Ding é o verdadeiro segredo" (Lacan, 2008, p. 60, grifo do autor). Ding seria o componente "originalmente, isolado pelo sujeito em sua experiência do Nebenmensch como sendo, por sua natureza, estranho, Fremde" (Lacan, 2008, p. 67, grifos do autor). Ding consistiria no primeiro exterior a partir de onde se dirige o encaminhamento desejoso do sujeito e, a partir do complexo do próximo (Komplex des Nebenmenschen), das Ding é tida como esse objeto para sempre perdido que remonta ao Outro absoluto, a que se busca em vão reencontrar (Jorge, 2008).

A via do princípio de prazer orienta o encadeamento das representações em direção à Coisa, no qual, ao mesmo tempo em que se aproxima dela, mantém uma distância suficiente que caracteriza o movimento do eterno reencontrar. A transferência de quantidade de energia de representação em representação mantém o esforço em alcançar o objeto, sempre a uma distância assegurada daquilo que realmente se almeja.

Para Lacan (2008), a Coisa é dotada de centralidade - é o primeiro interior que foi excluído - e a remete a um gozo primordial que orienta a cadeia das Vorstellungen:

[...] esse das Ding, esse Outro pré-histórico impossível de esquecer, do qual Freud afirma a necessidade da posição primeira sob a forma de alguma coisa que é entfremdet, alheia a mim, embora esteja no âmago desse eu, alguma coisa que, no nível do inconsciente, só uma representação representa. (Lacan, 2008, p. 89, grifos do autor)

A Coisa refere-se ao primeiro interior cernido devido a sua exclusão ou um gozo absoluto que só existe a partir da barreira da linguagem, remontando ao Outro pré-histórico. A linguagem produz o gozo como o que existia antes da sua intervenção (Braunstein, 2007), sendo esta sua função: a palavra mata a Coisa. Dessa forma, pertence ao campo do real, mas está, nas neuroses, circundada pelo simbólico. Ela surge como esse primeiro real inacessível, um exterior que antes fora interior, um estranho que é familiar. Assim, falando a respeito dessa origem mitológica do gozo, temos a relação edificada entre Coisa e palavra, sendo a primeira caracterizada como "o que, do real primordial, diremos, padece do significante" (Lacan, 2008, p. 144). É a Coisa que se torna esvaziada de gozo devido à ação do significante, o que não ocorre na melancolia, onde se torna um a mais que se apresenta para o sujeito a partir do objeto $a$ em sua face real, mas qual seria o estatuto desse objeto?

O objeto a, tal como elaborado por Lacan (2005), antes de ser um conceito é, sobretudo, uma letra, cujo caráter formal articula-se à nomeação de um objeto que possibilite a produção de construções clínicas. No ano desse seminário, a intenção era trabalhar a angústia, mas o ponto final da trajetória precipitou o conceito de objeto $a$. Para Nasio, o objeto $a$ teria surgido a partir da "impossibilidade que a psicanálise tem de definir exatamente o gozo" (Nasio, 2011, p. 61), de forma 
que é a sua construção que torna praticável trabalhar com esse real incognoscível. O gozo produz vestígios sensíveis que estão localizados fora do corpo, caracterizando justamente o objeto a como resto de gozo oriundo do real; resíduo não passível de assumir uma imagem.

Lacan (2005) definirá o objeto a tendo como norte a relação estabelecida entre o Outro originário como reduto do significante e o sujeito mítico que deve se situar como marcado pelo significante. Surge, com isso, o primeiro esquema da divisão, no qual

[...] o sujeito dependente desse Outro inscreve-se como um cociente. É marcado pelo traço unário do significante no campo do Outro. Não é por isso, se assim posso dizer, que ele corta o Outro em rodelas. Há, no sentido da divisão, um resto, um resíduo. Esse resto, esse Outro derradeiro, esse irracional, essa prova e garantia única, afinal, da alteridade do Outro, é o a. (Lacan, 2005, p. 36)

Nessa ocasião, o objeto $a$ é apresentado como o resto da operação de divisão entre sujeito e o Outro a partir do corte efetuado pelo significante. Retomando as elaborações sobre o esquema óptico, Lacan abordará a constituição imaginária do sujeito em relação ao espelho plano do Outro e ao investimento especular:
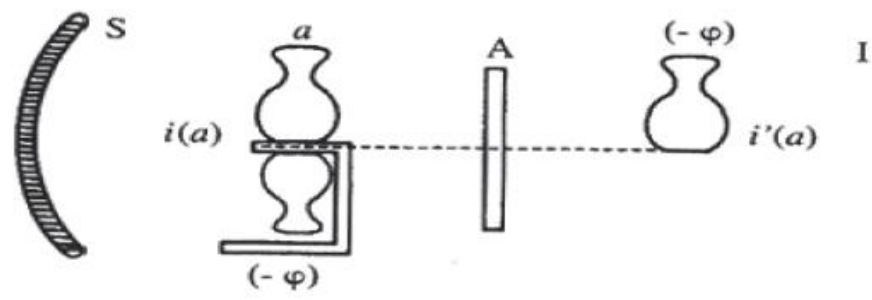

Figura 1: esquema óptico simplificado (Lacan, 2005, p. 49).

Nesse esquema, observamos que nem todo investimento libidinal passa pela imagem especular, há um resto. Aí entra em questão a diferença fundamental entre o menos $p h i(-\phi)$, o falo, e a constituição do pequeno $a$. Em tudo que se refere a uma demarcação imaginária, o falo surge em forma de lacuna, considerando a imagem virtual - $i^{\prime}(a)-$, ou seja, imagem do corpo funcionando na materialidade do sujeito como objeto investido de libido. De um lado, tem-se essa reserva operatória de libido, imaginariamente imperceptível, embora ligada a um órgão assimilável, que deverá entrar em ação para a satisfação do desejo: o falo. De outro lado, o objeto pequeno $a$, "que é o resto, o resíduo, o objeto cujo status escapa ao status do objeto derivado da imagem especular, isto é, às leis da estética transcendental" (Lacan, 2005, p. 50).

Ainda, com esse esquema, podemos intuir que o objeto $a$ é parte de uma anterioridade no que se refere à própria constituição do sujeito como barrado e que surge como resto a partir da 
operação de divisão entre o sujeito e o Outro. Antes do estádio do espelho, aquilo que será i(a), ou seja, a imagem real de $a$, encontra-se no disperso dos pequenos a característico do autoerotismo. É a partir da constituição da imagem real que se dará o domínio dessa multiplicidade de objetos $a$, pedaços do corpo original captados nesse momento e que são anteriores à constituição do sujeito.

Nas três últimas aulas do citado seminário, Lacan trabalhará a constituição do objeto a como objeto caído e como objeto cedido. Para Soler (2012), a queda do objeto diz respeito à operação chamada por Lacan de separtição, processo que ocorre entre o objeto e o sujeito, isso que do ser não passa pelo crivo do significante. Essa separtição produzir-se-ia no nível do real, melhor dizendo, no nível do próprio corpo, de forma que a separação entre o sujeito e objeto a pode ser equiparada à separação de um objeto, que permaneceu ligado ao gozo, e um corpo esvaziado de gozo. O objeto a como caído é singular, não possui imagem. Por outro lado, a cessão do objeto refere-se a uma operação da linguagem, que se passa entre o sujeito e o Outro. O objeto a como cedido se passa no nível dos fenômenos, sendo as substâncias episódicas desse objeto.

Lacan afirmará que, na psicose, "é a própria estrutura desses objetos, que os torna impróprios para a 'egoização" (Lacan, 2005, p. 134), de forma que nos leva a constatar que o corte desses objetos, concernentes à fase autoerótica, não ocorre de maneira similar nas neuroses. Sobre essa separação característica do começo, que remete à leitura de Soler (2012) sobre o processo de separtição, não se trata do corte entre a criança e a mãe, mas sim, de um pedaço do próprio corpo, de uma parcela do gozo primordial, sendo isso que é perdido e instaurado como um a menos na neurose. Na psicose, esse processo não é autenticado por um corte bem estabelecido. Por isso, "para dizer as coisas sumariamente, quando se trata do perverso ou do psicótico, a relação da fantasia ( $\$ \diamond a$ ) institui-se de tal modo que o a fica em seu lugar do lado da i(a)" (Lacan, 2005, p. 154, grifos do autor).

Considerando essa relação entre i (a) e a na psicose, como esse resto de gozo relacionado a um pedaço da ordem do real do próprio corpo que está sempre se fazendo presente, pensamos poder estabelecer uma relação entre o que Freud (1917[1915]/2004) postulou como sendo a relação do melancólico com a Coisa destituída dos seus atributos e o objeto a situado por Lacan ao lado de $\mathrm{i}(\mathrm{a})$, como esse resto de gozo:

O que distingue o que é próprio do ciclo mania-melancolia de tudo o que caracteriza o ciclo ideal da referência ao luto e ao desejo, só podemos apreendê-lo ao acentuar a diferença de função entre, por um lado, a relação de $a$ com $i(a)$ no luto, e, por outro, no outro ciclo, a referência radical ao $a$, mais arraigada para o sujeito que qualquer outra relação, mas também intrinsecamente desconhecida, alienada, na relação narcísica. (Lacan, 2005, p. 364, grifos do autor) 
Assim, constata-se que o objeto $a$ (referência primordial a esse pedaço do corpo) não sofre o domínio da palavra na psicose e, precisamente, no que se refere ao ciclo mania-melancolia observa-se uma relação mais radical com o $a$, dado estar aí destituído das suas vestes imaginárias.

\section{O processo de identificação na afecção melancólica}

Considerando os pressupostos trabalhados anteriormente sobre a perda específica, podemos avançar em direção às particularidades que envolvem o processo de constituição melancólica. Freud (1917[1915]/2004) constata que os pacientes melancólicos apresentam um traço que lhes é próprio, a depreciação do sentimento de autoestima, acompanhado por recriminações intensas feitas por uma instância crítica que, dirigidas ao próprio eu, subjuga-o, deixando-o sem recursos. Por isso, o melancólico dirige as mais altas injúrias para seu eu, afirmando que este não tem valor, é inútil e de moral desprezível, recriminando-se e esperando sofrer algum tipo de punição e castigo. Ele não afirma que houve uma mudança na sua vida que o deixou nesse estado, ao contrário, estende sua autocrítica em direção ao passado e afirma nunca ter estado ou sido melhor. A esse delírio de insignificância são acrescentados quadros de insônia e recusa alimentar, elucidando mais uma vez o fato de que a inibição melancólica, por tão acentuada, gera uma submissão da pulsão que leva todo ser vivo a se apegar à vida. Freud (1917[1915]/2004) advoga que, de algum modo, o sujeito parece ter razão ao se descrever assim, o que nos faz até mesmo concordar com tais acusações: ele parece ser realmente carente de interesses, fadado a uma incapacidade de amar e trabalhar conforme se avalia. Esse estado, secundário, é consequência do trabalho psíquico que está consumindo seu eu e causando inibições que, conforme discutimos anteriormente, pode se relacionar ao desfazer das associações e a retração para o interior, geradoras da quebra da ligação entre representações de coisa e representações de palavra.

Freud (1917[1915]/2004, partindo da constatação das abrangentes autoacusações do melancólico, assevera que se torna difícil evitar o pensamento de que estas não se encaixam ao certo na pessoa, mas que poderiam muito bem dirigir-se a alguém que o sujeito amou anteriormente. Eis o ponto-chave para se compreender as principais manifestações clínicas da melancolia: "as autorrecriminações são recriminações dirigidas a um objeto amado, as quais foram retiradas desse objeto e desviadas para o próprio Eu" (Freud, 1917[1915]/2004, p. 107).

A constituição da melancolia pode assim ser resumida: inicialmente, houve uma escolha de objeto, que, devido a uma ofensa real ou decepção, foi estremecida. O eu, no lugar de retirar progressivamente o investimento no objeto e deslocar para outros objetos, recolheu essa libido para si mesmo, produzindo uma identificação ao objeto que tinha sido abandonado. Assim, diz Freud (1917[1915]/2004, p. 108): "a sombra do objeto caiu sobre o Eu" - a perda do objeto torna-se uma perda do próprio eu. A partir dessa identificação, a instância crítica passa a julgar o eu como se ele fosse o próprio objeto perdido. Por isso, as autoacusações dos melancólicos refletem o desagrado 
moral para com o próprio eu que agora porta toda hostilidade da instância crítica, outrora dirigida ao objeto.

Comparando as características do trabalho de luto, já descritas, e o processo constitutivo da melancolia, podemos sintetizar: ambos são reações a uma perda. No entanto, a perda do luto é conhecida, mas, dada sua condição específica, a da melancolia é enigmática. Na melancolia, o investimento depositado no objeto provou ser frágil e foi retirado, elucidando que, por um lado, existe a exigência de que tenha ocorrido uma forte fixação no objeto amado, por outro, que esse investimento objetal tenha se mostrado pouco resistente. Esse fator dá margem à hipótese de que a escolha de objeto, na melancolia, seja de base narcísica: "poderíamos incluir sem hesitação na caracterização da melancolia a ideia de que ocorre uma regressão do investimento de carga depositado no objeto para a fase oral da libido - fase ainda pertencente ao período do narcisismo" (Freud, 1917[1915]/2004, p. 109).

Com isso, surgem importantes diferenças a serem consideradas, pois nas neuroses, principalmente na histeria, também são frequentes as identificações com o objeto. Conforme Florence, a identificação histérica é uma identificação imaginária "do desejo com o desejo do outro, com o qual só há identificação na medida em que se é portador da marca de um desejo insatisfeito" (Florence, 1994, p. 18). Freud (1921/2006) aborda esse tipo de identificação a partir do exemplo de Dora, que imitava a tosse do seu pai, ou seja, imitava o sintoma da pessoa amada. Ou ainda, por meio do exemplo da menina que desenvolve o mesmo sintoma que a mãe, ilustrando um desejo hostil de ocupar o lugar dela frente ao pai.

A identificação neurótica, ilustrada pela histeria, possui a singularidade de estar dominada por um conflito, por orientações contraditórias de desejo, nas quais o sintoma abarca tanto a reprodução de algum traço da pessoa amada, como no caso Dora, quanto algum traço do rival, como no caso da imitação da tosse da mãe. Essa identificação possui um caráter bastante limitado, no qual o investimento no objeto continua a existir, mas restrito a determinados traços e ações (Freud, 1921/2006). De maneira geral,

Essas identificações são a apropriação (Aneignung) de qualidades, e até de sintomas, do objeto da rivalidade ou do amor. Elas se dão por meio de uma regressão dos investimentos de objeto, para garantir o recalcamento desses últimos. Essas identificações (histéricas) são extremamente limitadas e recebem do objeto um só traço. (Florence, 1994, p. 135, grifos do autor)

Nas neuroses, existe a identificação com um traço do objeto, fator responsável pelo caráter constitutivo do eu. Quando o investimento objetal precisa ser abandonado, inicia-se o processo de luto, no qual as ligações ao objeto vão sendo paulatinamente desfeitas, ocasionando a introjeção de um traço desse objeto perdido no eu, para que o isso abdique da satisfação obtida com aquele 
objeto (Freud, 1923/2007). Por isso, o luto exige um trabalho demorado e grande gasto de energia, mas que, uma vez concluído, o eu se apropria de um traço do objeto perdido e volta a direcionar seus investimentos para outros objetos. O eu seria, dessa forma, um precipitado dos investimentos objetais abandonados (Freud, 1923/2007) e as identificações seriam responsáveis por produzir o caráter do eu. Adotando as características do objeto, o eu pode se fazer amado pelo isso.

Nas identificações narcísicas, a exemplo da melancolia, o investimento libidinal no objeto é abandonado e recolhido no eu, produzindo a identificação do eu ao objeto. Não se trata da identificação a um traço específico, mas à totalidade do objeto - o eu resta completamente subjugado. Tais identificações são mais primitivas e transformam a relação objetal, que são baseadas em um ter, em uma relação mais arcaica de ser o objeto, conforme a fase oral do desenvolvimento libidinal, na qual se pretendia incorporar o objeto perdido.

O estudo da identificação melancólica permite o entendimento do processo de constituição do eu nas patologias em geral, pois nela a supremacia da identificação ao objeto perdido provoca uma grave cisão do eu, em que uma parte absorve todo o sadismo anteriormente dirigido ao objeto, que passa a julgar o eu como se fosse o próprio objeto. A escolha objetal narcísica regride sem limites ao estádio mais original da constituição psíquica, no qual os contornos do eu estão ainda indefinidos, daí sua fragilidade (Florence, 1994).

A premissa de que na melancolia se dá a identificação ao objeto perdido explica o tipo de perda inconsciente, observado por Freud nas suas cartas a Fliess, que explica o buraco na esfera psíquica provocado pela quebra das ligações entre representações de coisa e representações de palavra, tal como descrito no esquema sexual do Rascunho $G$ : uma ferida aberta que absorve de todas as direções a energia de investimento para si, empobrecendo e esvaziando o eu (Freud, 1895/2006).

Com esses achados, torna-se possível pensar que o objeto ao qual o sujeito melancólico se identifica, descrito por Freud como o objeto perdido das paragens do narcisismo primitivo, é o que estabelecemos anteriormente como a referência mais direta à Coisa, ou seja, o objeto $a$ em sua forma mais radical. O melancólico, buscando barrar esse excesso de gozo que sempre bate a sua porta, identifica-se a esse objeto - fruto das suas primeiras relações com seu próprio corpo - como única alternativa para evitar sua desintegração.

Tal identificação não é com o objeto a como causa de desejo e sim com esse pedaço do que existia antes do fracionamento do sujeito produzido pela linguagem, conforme ilustrado pelo processo de separtição, anteriormente aludido. Nela, o objeto a como causa de desejo não está autorizado simbolicamente pela significação fálica, que, nas neuroses, serve para vestir o objeto e mascará-lo.

Essa constatação torna-se possível graças à diferença, estabelecida por Lacan, no final do seu seminário sobre a angústia, entre o processo de luto e a melancolia. Quando esclarece que, no primeiro, a fantasia reveste os objetos imaginários, enquanto, na segunda, a fantasia não exerce 
essa mesma função e que se vê é a relação é com um a em sua face real, o que aponta muito mais a algo da ordem do delírio.

Para Lacan (2005), o luto consiste em um trabalho para manter e sustentar todos os vínculos com o objeto, numa tentativa de efetivar, pela segunda vez, a perda do objeto amado, seu desligamento, na medida em que ele é sempre reencontrado. Isso ocorre no sentido de restabelecer a ligação com o principal objeto da relação, que seria o objeto a mascarado, para o qual seria possível eleger um substituto. E não é assim que se dá o processo de luto tal como descrito por Freud em 1915 ? O luto consiste no desfazer dos laços que prendiam o eu ao objeto, a fim de poder ficar livre de inibições e se ocupar do investimento em novos objetos. Ou, em termos lacanianos: encontrar novas roupas imaginárias para o objeto a que movimenta a relação ao desejo. Dessa forma, no luto, o desejo se prende à i (a), formulação pela qual todo amor é estruturado. A possibilidade da elaboração de i(a), imagem especular, observa-se graças à elaboração de um luto e a identificação, nesse caso, refere-se a um traço, reduzido a um aspecto imaginário.

Na melancolia, o processo de recolhimento da libido para o eu não colhe bons resultados, "porque o objeto supera sua direção. É o objeto que triunfa" (Lacan, 2005, p. 364). Trata-se, aí, de algo distinto: não há a reintegração de outras vestes narcísicas para o objeto diante da perda, mas, sim, a anexação do próprio objeto ao eu, que fica dominado por essa radicalidade e empobrece, ponto máximo de identificação ao objeto a como caído, impossível de ser extraído. O melancólico, por não conseguir fazer o luto do objeto, rejeita a perda ao introduzi-lo no eu, sendo consumido por ele. Isso exige que

[...] o melancólico, digamos, atravesse sua própria imagem e primeiro a ataque, para poder atingir, lá dentro, o objeto a que o transcende, cujo mandamento the escapa - e cuja queda o arrasta para a precipitação suicida, com o automatismo, o mecanicismo, o caráter imperativo e intrinsecamente alienado com que vocês sabem que se cometem os suicídios de melancólicos. (Lacan, 2005, p. 364)

Atacar a própria imagem é uma tentativa de estabelecer a separação desse objeto caído, sem mediação fálica, acrescido de gozo e ao qual o eu encontra-se identificado. Sendo assim, as autoacusações melancólicas referem-se a sua posição de objeto dejeto destituído de qualquer valor narcísico. Esse aspecto está aliado à ação do supereu bastante severo, que promove um gozo descendente do isso, tornando-o um peso na melancolia, tributário de uma impossível mediação.

\section{Considerações finais}

Nosso propósito constituiu-se em explorar o objeto na melancolia pela via freudiana, a partir da ideia de uma perda específica de libido, que promove um desligamento das associações entre neurônios e um buraco na esfera psíquica. Esse desligamento das associações nos fez observar a 
ocorrência de uma separação entre a Coisa e seus atributos, um abandono pela libido. Compreendemos, também, que na melancolia existe uma relação mais radical à das Ding, destituída dos seus predicados, corroborada pela premissa de que o processo melancólico se passa no reino do inconsciente, sob a égide dos traços mnemônicos de coisa. Constatamos que o conceito de das Ding, em seu sentido freudiano, permitiu que Lacan levantasse a tese segundo a qual a Coisa seria dotada de uma extimidade - ela seria esse primeiro exterior ligado a um gozo primitivo - e que foi cernida pela linguagem.

Observamos que o objeto $a$, em sua face real, ao contrário do que ocorre nas neuroses, não é, na melancolia, separado por obra da função fálica estabelecida pelo significante Nome--do-Pai em atividade na dialética da castração, despojando-a da possibilidade de uma identificação simbólica, onde o ponto de partida é o luto incestuoso dos objetos. Em tal estrutura, melancolia, a separação do objeto $a$ não se estabelece e o luto não cumpre a sua função, o que explica seus principais agravantes: empobrecimento e poderosas inibições do eu, supereu crudelíssimo, de onde pendem as mais fortes acusações que podem levar ao delírio expectante de punição e até à morte.

\section{Referências bibliográficas}

Braunstein, N. (2007). Gozo. São Paulo: Escuta.

Florence, J. (1994). As identificações. As identificações na clínica e na teoria psicanalítica (pp. 115170). Rio de Janeiro: Relume-Dumará.

Freud, S. (2004). Luto e Melancolia. Escritos sobre a psicologia do inconsciente (Vol. 2, pp. 99-116). Rio de Janeiro: Imago (Trabalho original publicado em 1915).

Freud, S. (2006). Projeto para uma psicologia científica. In J. Salomão (Trad.) Edição standard brasileira das obras psicológicas completas de Sigmund Freud (Vol. 1, pp. 333-454). Rio de Janeiro: Imago (Trabalho original publicado em 1950[1895]).

Freud, S. (2006). Rascunho G. In J. Salomão (Trad.) Edição standard brasileira das obras psicológicas completas de Sigmund Freud (Vol. 1, pp. 246-253). Rio de Janeiro: Imago (Trabalho original publicado em 1895).

Freud, S. (2006). Psicologia de Grupo e a Análise do Ego. In J. Salomão (Trad.) Edição standard brasileira das obras psicológicas completas de Sigmund Freud (Vol. 18, pp. 81-154). Rio de Janeiro: Imago (Trabalho original publicado em 1921).

Freud, S. (2007). O Eu e o Id. In Escritos sobre a psicologia do inconsciente (Vol. 3, pp. 13-25). Rio de Janeiro: Imago (Trabalho original publicado em 1923).

Jorge, M. A. (2008). Fundamentos da psicanálise de Freud a Lacan (Vol. 1). Rio de Janeiro: Jorge Zahar.

Lacan, J. (2008). O seminário, livro 07: a ética da psicanálise . Rio de Janeiro: Jorge Zahar (Trabalho original publicado em 1959-1960). 
Lacan, J. (2005). O seminário, livro 10: a angústia. Rio de Janeiro: Jorge Zahar (Trabalho original publicado em 1962-1963).

Nasio, J.-D. (2011). Os olhos de Laura. Rio de Janeiro: Jorge Zahar.

Quinet, A. (2006). Psicose e laço social: esquizofrenia, paranoia e melancolia. Rio de Janeiro: Zahar.

Soler, C. (2012). Seminário de leitura de texto ano 2006-2007: seminário a angústia, de Jacques Lacan. São Paulo: Escuta.

Citacão/Citation: Barreto, C. M. E. \& Fontenele, L. (nov. 2015 a abr. 2016). Bases conceituais para o entendimento da identificação na melancolia: da identificação ao objeto perdido à identificação à face real do objeto a. Revista aSEPHallus de Orientação Lacaniana, 11(21), 16-31. Disponível em www.isepol.com/asephallus. doi: 10.17852/1809-709x.2019v11n21p16-31.

Editor do artigo: Tania Coelho dos Santos.

Recebido/Received: 24/11/2015 / 11/24/2015.

Aceito/Accepted: 18/12/2015 / 12/18/2015.

Copyright: (C) 2013 Associação Núcleo Sephora de Pesquisa sobre o moderno e o contemporâneo. Este é um artigo de livre acesso, que permite uso irrestrito, distribuição e reprodução em qualquer meio, desde que o autor e a fonte sejam citados/This is an open-access article, which permites unrestricted use, distribution, and reproduction in any medium, provided the author and source are credited. 